\title{
EDUCAÇÃO AMBIENTAL NO CONTEXTO ESCOLAR: PROJETO NA ESCOLA AGROAMBIENTAL EM CURRALINHO (PA)
}

\author{
Sabrina de Oliveira Farias ${ }^{1}$ \\ Larissa Martins Barbosa D'Arace ${ }^{2}$ \\ Klewton Adriano Oliveira Pinheiro ${ }^{3}$ \\ Francimary da Silva Carneiro ${ }^{4}$
}

Resumo: Esta pesquisa teve como objetivo avaliar a Educação Ambiental aplicada na rede pública de ensino, e expor de forma didática para os alunos sobre os cuidados que devemos ter com o meio ambiente dentro e fora da escola. Foram feitas palestras, oficinas e atividades recreativas dentro e fora da sala de aula, mostrando uma nova abordagem sobre a Educação Ambiental, onde se buscou tais ações a fim de informar sobre alimentação saudável, gerenciamento de resíduos e cuidados com o meio escolar em que vivem, visando a urgente necessidade que se têm em inserir a Educação Ambiental nas diversas áreas de ensino. Ao final do projeto encontrou-se nesses alunos mudanças de atitudes, incentivos para a cooperação e a solidariedade, de forma sustentável através da Educação Ambiental.

Palavras-chave: Sustentabilidade; Horta Escolar; Reciclagem; Atividades Recreativas.

${ }^{1}$ Instituto Federal de Educação, Ciências e Tecnologia do Pará.

E-mail: sabrina.agroportal@gmail.com

2 Embrapa Amazônia Oriental. E-mail: larissamartins350@gmail.com

${ }^{3}$ Instituto Federal de Educação, Ciências e Tecnologia do Pará.

E-mail: klewton.pinheiro@ifpa.edu.br

${ }^{4}$ Embrapa Amazônia Oriental. E-mail: francimarycarneiro@gmail.com 


\section{Introdução}

A questão ambiental requer novas formas de abordagem, integrando as várias áreas de conhecimentos e tendo como foco principal o despertar da consciência, principalmente das crianças e dos adolescentes, para que assim novos hábitos possam ser formados, para direcionar a sociedade a utilizar os recursos naturais de forma sustentável. Nesta perspectiva, a Educação Ambiental apresenta várias soluções para os problemas ambientais e sociais (SOUZA, et al, 2013).

A Lei Federal ํo 9.795/1999 que institui a Política Nacional de Educação Ambiental (PNEA), a define:

os processos por meio dos quais o indivíduo e a coletividade constroem valores sociais, conhecimentos, habilidades, atitudes e competências voltadas para a conservação do meio ambiente, bem de uso comum do povo, essencial à sadia qualidade de vida e sua sustentabilidade" e frisa a sua incorporação como prática integrada, contínua e permanente em todos os níveis e modalidades do ensino formal. Para tanto, o artigo 11 desta lei destaca a importância da dimensão ambiental estar presente no currículo de formação dos professores de todas as áreas do conhecimento, ou presente como formação complementar para professores em exercício (BRASIL, 1999).

A Educação Ambiental (EA) sugere que o conhecimento científico, abordado de forma contextualizada e com problemáticas pertinentes à realidade, permita ao aluno se posicionar acerca de questões polêmicas do nosso tempo, como os desmatamentos, o acúmulo de poluentes, o aquecimento global, as alterações climáticas, a produção de organismos geneticamente modificados e suas implicações à saúde e ao ambiente entre outros temas. Sugerem que o Ensino de Ciências da Natureza ofereça contribuições para a percepção das problemáticas socioambientais inerentes ao nosso contexto sociocultural (MEDEIROS et al., 2011).

O trabalho de Educação Ambiental deve ser desenvolvido a fim de ajudar os alunos a construírem uma consciência global das questões relativas ao meio para em relação à sua proteção e melhoria. Para isso é importante que possam atribuir significado e importante valorização que aprendem sobre a questão ambiental. E esse significado é resultado da ligação que o aluno estabelece entre o que aprende e a sua realidade cotidiana e da possibilidade de utilizar o conhecimento em outras situações (BRASIL, 2002).

Lima (2004) afirma que os alunos que não são aproximados do objeto de estudo (no caso o meio ambiente) são impossibilitados no engajamento de diversas questões surgidas na vida contemporânea e não terão uma postura crítica de sua realidade. Segundo o autor essa aproximação procura despertar o interesse do aluno através da problematização pertencente ao seu mundo,

revista brasileira educação ambiental 
buscando desenvolver o pensamento crítico e criativo. A escola é um espaço concedido para estabelecer trocas e informações, um eventual lugar que estimulem os alunos a terem ideias e postura de cidadãos cientes de suas responsabilidades e, fundamentalmente, integrantes do meio ambiente (CUBA, 2010).

As questões ambientais estão cada vez mais presentes no cotidiano da sociedade, contudo, a Educação Ambiental é essencial em todos os níveis dos processos educativos e em especial nos anos iniciais da escolarização, já que é mais fácil conscientizar as crianças sobre as questões ambientais do que os adultos (MEDEIROS et al., 2011).

É necessário que os alunos saibam a importância que o meio ambiente tem para a sobrevivência e tenham consciência do cuidado aos recursos naturais, pois assim tais recursos naturais estarão sempre disponíveis para a sociedade de forma que não sejam extintos. Neste contexto, entra o papel do professor como educador de servir como agente fundamental nessa tarefa de transformação e aprendizagem, principalmente, para as crianças e jovens que precisam conhecer a importância do desenvolvimento sustentável. Portanto, necessita-se inserir a Educação Ambiental nos mais diversos lugares da sociedade, visto que é importante para a sociedade, economia e meio ambiente.

A coleta seletiva dos resíduos sólidos e sua reciclagem é importante para diminuir a degradação do meio ambiente e é sustentável, pois diminui tais resíduos no meio ambiente, dessa forma mantem a qualidade de vida e do meio ambiente e gera renda, pois tais resíduos podem ser torna produtos comercializados, após o processo de reciclagem. Além da coleta seletiva e reciclagem, tem o plantio de horta que é de fundamental importância para a sociedade, fornece alimento de boa qualidade, diminui os custos com a alimentação.

Considerando a hipótese: se a Educação Ambiental for implantada nas escolas públicas do ensino fundamental, logo os alunos terão mais consciência da preservação do meio ambiente e sustentabilidade. Diante disso, este trabalho tem como objetivo avaliar a Educação Ambiental na rede pública de ensino e expor de forma didática para os alunos sobre os cuidados que devemos ter com o meio ambiente dentro e fora da escola.

\section{Materiais e métodos}

\section{Área de estudo}

O Projeto de Educação Ambiental foi executado na Escola Municipal de Ensino Fundamental Agroambiental Professora Lindalva Pinho, que fica localizada na Av. Floriano Peixoto, S/N, Bairro do Cafezal, Cidade de Curralinho - Marajó - Pará. A referida escola atende uma clientela de alunos do $1^{\circ}$ ano $9^{\circ}$ ano e EJA de $1^{\circ}$ a $4^{\circ}$ Etapa. O público-alvo do projeto foram cerca de 60 alunos de duas turmas do $5^{\circ}$ ano, divididos em dois turnos (manhã e tarde). 


\section{Coleta e análise de dados}

O projeto foi desenvolvido em uma semana (05 dias) através de atividades de palestras e oficinas. As palestras foram executadas no período da manhã, nos dois primeiros dias de realização do projeto. De acordo com o Quadro 1:

Quadro 1: Palestras e assuntos.

\begin{tabular}{ll}
\hline Palestra & \multicolumn{1}{c}{ Assunto } \\
\hline $1^{\circ}$ dia & $\begin{array}{l}\text { A importância da preservação da fauna e da flora, racionamento da água, } \\
\text { poluição do solo, da água e do ar, crimes ambientais e a biodiversidade local. }\end{array}$ \\
$2^{\circ}$ dia & $\begin{array}{l}\text { O lixo no planeta, o destino final para o lixo sólido e orgânico, reciclagem e adubo } \\
\text { a partir dos resíduos orgânicos em hortas escolares, de uma forma lúdica e } \\
\text { dinâmica para que não se tornasse cansativo para aos alunos, fazendo sempre } \\
\text { uma reflexão e uma pequena atividade com a turma. }\end{array}$ \\
\hline
\end{tabular}

As oficinas foram realizadas no decorrer da semana, durante o período da manhã, sempre com intervalo para o lanche, descritas a seguir de acordo com o Quadro 2.

Quadro 2: Oficina e assunto.

\begin{tabular}{cl}
\hline Oficina & Assunto \\
\hline 10- Oficina da Coleta Seletiva & Foram confeccionadas lixeiras com as cores da coleta \\
& seletiva a partir de recipientes de descarte comercial, \\
& para serem implantadas nas dependências da escola. \\
& Para isso foram feitos trabalhos com pintura e colagens. \\
& E posteriormente foi feito o trabalho de coleta de lixo \\
& dentro da escola e sua adequada separação nas lixeiras.
\end{tabular}

2-- Oficina de Reciclagem

3-o Oficina de Plantio
Onde foram trabalhados princípios de reciclar o lixo, orientações e pôr fim a confecção dos objetos e brinquedos a partir dos materiais recicláveis que os alunos trouxeram de casa e outros resíduos encontrados na escola. Foram feitos trabalhos de corte, pintura e colagens.

Foi realizada esta oficina no último dia com os alunos, onde já existia uma horta nas dependências da escola, mas até então sem uso, e os alunos tiveram a oportunidade de ter o contato com o ambiente natural, aprenderam o processo de adubagem da terra, dicas de como plantar sementes e mudas, como regar e cuidar da planta, para futuramente servir como complemento para a merenda escolar.

Este trabalho foi dividido em duas etapas, onde na primeira parte tratouse das atividades desenvolvidas no projeto e na segunda etapa a aplicação do questionário para verificar se todos os alunos aprenderam, conforme se observa a seguir. 


\section{Apresentação do projeto}

\section{$1^{\circ}$ DIA - 06/06 (segunda-feira): apresentação do projeto, fala do diretor e primeira palestra}

As atividades do projeto iniciaram com a fala dos professores que acompanharam as atividades junto às turmas, em seguida o diretor da escola deu boas vindas e falou da importância dessa iniciativa para a formação sociocultural dos alunos, continuando os trabalhos, foram distribuídos os folders, no qual foi apresentado á turma o projeto e o cronograma de atividades. Logo após as apresentações, foi feita uma dinâmica de apresentação com os alunos para conhecê-los.

Utilizando um barbante que circulou pelas mãos de todos os alunos onde cada um disse seu nome e idade, ao final formando uma teia, refletimos sobre a importância do trabalho coletivo para a construção de algo, no caso a construção do projeto na escola, e que aquele estaria sendo nosso primeiro laço e se alguém faltasse durante a semana de atividades, seria como soltar uma das pontas da teia, deixando o grupo desestruturado, e assim todos assumimos o compromisso com as atividades durante a semana.

O primeiro dia de atividades foi muito mais para desinibir os alunos com a presença do projeto, foram feitos diálogos sobre os temas e perguntas básicas à turma, sobre: O que entendem por Meio Ambiente? Qual a relação com o Meio Ambiente? Quais as atividades de Educação Ambiental já desenvolveram na escola? E assim os alunos foram criando uma confiança e despertando perguntas. O vídeo foi uma grande novidade na sala de aula, no qual inclusive, pediram para que reproduzisse pela segunda vez.

\section{$2^{\circ}$ DIA - 07/06 (terça-feira): segunda palestra}

No segundo dia, as atividades iniciaram com uma dinâmica envolvendo uma canção em sala para testar a capacidade de memória e coordenação motora dos alunos. A canção falava sobre o comportamento dos homens em uma tribo indígena, foi escolhida, pois era uma linguagem fácil de ser entendida pelos alunos, tendo em vista que o projeto foi desenvolvido em uma região amazônica, na ilha do Marajó. Foi importante para que os alunos observassem os cuidados que os homens deviam tomar, estando em um ambiente natural, onde os índios viviam em harmonia com os animais e árvores.

\section{$3^{\circ}$ DIA - 08/06 (quarta-feira): primeira oficina (oficina da coleta seletiva)}

No terceiro dia de atividades, foi iniciada a primeira oficina, onde foi instigada a mente dos alunos a verem a mesma como instrumento de zelo pela escola e trabalho em equipe. Para a oficina, foram distribuídos às crianças, luvas de plástico e sacos para lixo a cada cinco alunos, formadas as equipes e dadas às orientações de como se realizaria a atividade, tratamos sobre a importância de utilizar luvas ao recolher qualquer tipo de lixo por conta de suas 
contaminações, e o descarte correto, tratando-se especialmente de vidros quebrados, latas cortadas e lixo do banheiro.

\section{$4^{\circ}$ DIA - 09/06 (quinta-feira): segunda oficina (oficina da reciclagem)}

Foi executada a oficina de reciclagem, que baseada nas palestras sobre lixo, trabalhou-se a Educação Ambiental como forma de reaproveitamento do nosso lixo e suas infinitas possibilidades de transformação. As crianças foram orientadas a trazer para este dia todo o lixo que eles conheciam como reciclável, onde na palestra já havíamos tratado dos lixos recicláveis e não recicláveis, para então dar início a oficina de reciclagem dos lixos tragos pelas crianças.

Para que os alunos iniciassem a confecção dos objetos a serem reciclados, foi feita uma amostra em vídeo de alguns objetos transformados a partir de garrafa pet, cd's, diversos recipientes, papeis e outros, e ensinados alguns os quais eles se identificassem e escolhessem, depois de dadas as orientações cada grupo se responsabilizou por um brinquedo ou objeto a confeccionar e com a ajuda dos professores para ferramentas de corte e cola com refil quente.

\section{$5^{\circ}$ DIA - 10/06 (sexta-feira): terceira oficina (oficina de horta e plantio)}

Para esta oficina foram colocados em prática alguns conceitos aplicados em sala nas palestras, de como plantar e como cuidar de uma horta. Com o auxílio do responsável pela horta, a qual já era existente na escola, mas um pouco descuidada. Antes de iniciar as atividades, em duas semanas anteriores já havia feito um trabalho de limpeza, adubação e plantio das mudas (Figura 1), para que no dia da oficina as crianças apenas fossem plantar e regar as mudas.

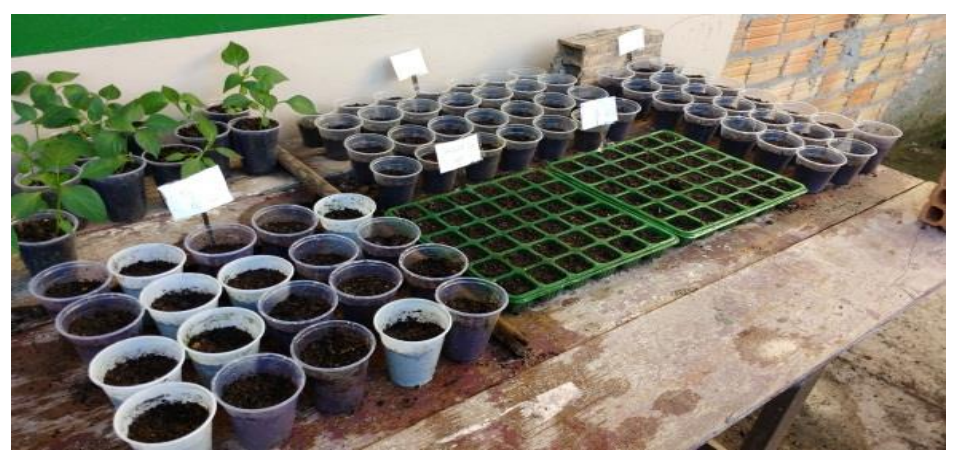

Figura 1: Mudas plantadas em copos plásticos com 02 semana antes de serem utilizadas na oficina de plantio.

Tratando-se de Educação Ambiental e redução de lixo, a ideia foi elaborar uma horta suspensa feita com garrafas pet, enfatizando a ideia de se reaproveitar todo o lixo encontrado. Foram cortadas as garrafas e pregadas em um painel de madeira, todas foram furadas para que o oxigênio e água 
circulassem sem interferir no desenvolvimento das mudas, em seguida cada criança em sua vez apanhava a terra já adubada para preparar o espaço que a planta ficaria, e assim foram preenchidos todos os recipientes de garrafa pet, após essa etapa, cada criança ficou com uma muda para plantar nas garrafas, e com cuidado de uma em uma elas foram orientadas do cuidado de tirar as mudas dos copos para outro ambiente (FIGURA 5). Outras mudas foram plantadas nos espaços que já existiam na horta, para serem reaproveitadas. Todas as mudas plantadas foram de hortaliças, dentre elas: Brassica oleracea L. (couve), Cucumis anguria L (maxixe), Allium schoenoprasum L. (cebolinha), Cucumis sativus L. (pepino), Lactuca sativa L. (alface), Phaseolus vulgaris L. (feijão) e Coriandrum sativum Lineu (coentro).

Ao final da oficina foi feito uma reflexão da importância da horta na escola, tanto para Educação Ambiental dos alunos como para a sua própria educação alimentar, de como as hortaliças que eles plantaram na escola seria servido na merenda escolar que era consumido na escola.

\section{Resultados e Discussões}

\section{$1^{\circ}$ DIA - 06/06 (segunda-feira): apresentação do projeto, fala do diretor e primeira palestra.}

A primeira etapa do trabalho constou-se da palestra do projeto, da qual tiveram contatos com conceitos de meio ambiente, biodiversidade, fauna e flora, para depois discutir sobre sustentabilidade. Outros temas foram tratados como: biodiversidade, cultura amazônica, diversos tipos de poluição, suas causas e consequências, espécies ameaçadas de extinção, racionamento de água, dicas de como poupar água, desmatamento e crimes ambientais, onde os professores acrescentaram e relembraram os temas que já havia sido trabalhado em sala de aula.

Surgiram colocações, curiosidades e perguntas por parte dos alunos. Posterior ao debate na palestra foi reproduzido um vídeo sobre: Economia de água, o qual falava sobre maus hábitos com o desperdício de água e dicas de como poupá-la. Ao final da manhã foram distribuídas aos alunos duas atividades relacionadas à palestra do dia, uma delas foi para encontrarem as palavras em um diagrama e com as palavras encontradas formarem frases, algumas das palavras encontradas foram: peixes, rios, floresta, animais, ar, e a segunda atividade foram para eles desenharem em um papel em branco, como eles veem e conhecem o meio ambiente em que vivem.

$\mathrm{O}$ aspecto afetividade influi no processo de aprendizagem e o facilita, pois nos momentos informais, os alunos aproximam-se do professor, trocando ideias e experiências várias, expressando opiniões e criando situações para, posteriormente, serem utilizadas em sala de aula (MULLHER, 2002). 


\section{$2^{\circ}$ DIA - 07/06 (terça-feira): segunda palestra}

Foi ministrada a segunda palestra, que serviu como base teórica aos trabalhos que seriam executados ao longo do projeto durante a prática nas oficinas. Os temas abordados foram: O lixo no planeta, classificação dos tipos de lixos e destino final para eles, conceito de coleta seletiva e sua finalidade, reciclagem, minimização de lixo e a política dos $3 R$ 's que segue a ordem de Reduzir o consumo de enlatados, recipientes de vidro, caixas de longa vida, materiais descartáveis e sacolas plásticas, Reaproveitar tudo que for possível antes de jogar no lixo, por exemplo, uma garrafa pet para armazenar água e Reciclar o lixo, transformando-o em algum outro objeto para ser utilizado, conceito de compostagem e seu processo até chegar ao adubo final e a importância da horta nas escolas desde seu processo educacional até a alimentação saudável dos alunos.

Um vídeo (Figura 2a) foi exibido sobre coleta seletiva e ainda foi exposto um banner com informações sobre coleta seletiva. Com a finalidade de testar a atenção dos alunos para com o tema, foram distribuídas balas de doces para todos e ao final do dia seria feita a reflexão dessa dinâmica.

Como reforço ao conteúdo apresentado, junto com a reprodução do vídeo abrimos a roda para perguntas e reflexão dos alunos sobre o tema, em seguida os alunos confeccionaram cartazes com temas relacionados às palestras (Figura 1B). Ao final das atividades foi questionado: onde eles haviam jogado a embalagem das balas? Alguns haviam jogado na lixeira da sala, mas a maioria jogou no chão da sala, o que despertou certo constrangimento e imediatamente todos recolheram seu lixo, e voltamos a discutir sobre nossos hábitos em relação ao lixo, a dinâmica serviu como forma de reflexão e muitos ficaram sensibilizados e envergonhados com a atitude.

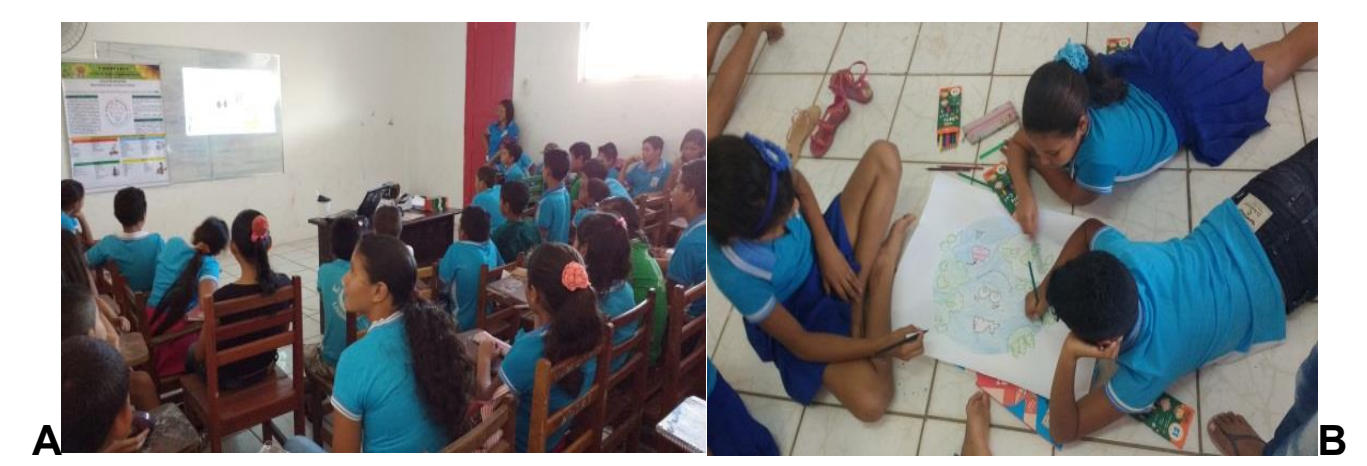

Figura 2: Alunos assistindo o vídeo $(\mathrm{A})$ e confeccionando cartazes para divulgarem nos corredores da escola o que aprendido em sala de aula (B).

Segundo Guimarães (1995) o processo de Educação Ambiental a conjunção do aspecto lúdico e criativo das atividades e dos procedimentos, são importantes para envolver o educando. Reforça, inclusive, que a "sensibilização deverá ser seguida com uma relação prazerosa dele com o processo". 
O contato com os alunos no segundo dia, já era de fácil aceitação, chegaram cedo e muito animados para as novidades que o projeto traria naquele dia. Notou-se grande empenho durante a dinâmica que envolveu a canção, houve muitas gargalhadas e muitos abraços, o que serviu para aproximar de alguma forma a turma que convive durante um ano. Os professores elogiaram a forma como o projeto estava mudando o comportamento dos alunos em sala e como o respeito entre os colegas e com os professores.

A Educação Ambiental deve ser acima de tudo um ato político voltado para a transformação social, capaz de transformar valores e atitudes, construindo novos hábitos e conhecimentos, defendendo uma nova ética, que sensibiliza e conscientiza na formação da relação integrada do ser humano, da sociedade e da natureza, aspirando ao equilíbrio local e global, como forma de melhorar a qualidade de todos os níveis de vida (CARVALHO, 2006).

\section{$3^{\circ}$ DIA - 08/06 (quarta-feira): primeira oficina (oficina da coleta seletiva)}

Já devidamente preparados, com os materiais de coleta em mãos foram direcionados para fora da sala e orientados a recolher todo o lixo que fosse encontrado nas dependências da escola (Figura 3a), e junto aos outros alunos que estavam no horário do intervalo ajudaram a fazer uma "varredura" na escola, recolhendo todo lixo que se encontravam, dada a tarefa de qual seria a equipe a recolher mais lixo, e como forma de mutirão, os professores, funcionários e outros alunos ajudaram nessa tarefa que serviu como incentivo para todos tomarem consciência e manter limpo e conservado o ambiente escolar. Ao final da tarefa o lixo recolhido foi encaminhado para os grandes recipientes onde são acolhidos todo o lixo da escola, no retorno para a sala foi feita a reflexão com a turma sobre a atividade executada.

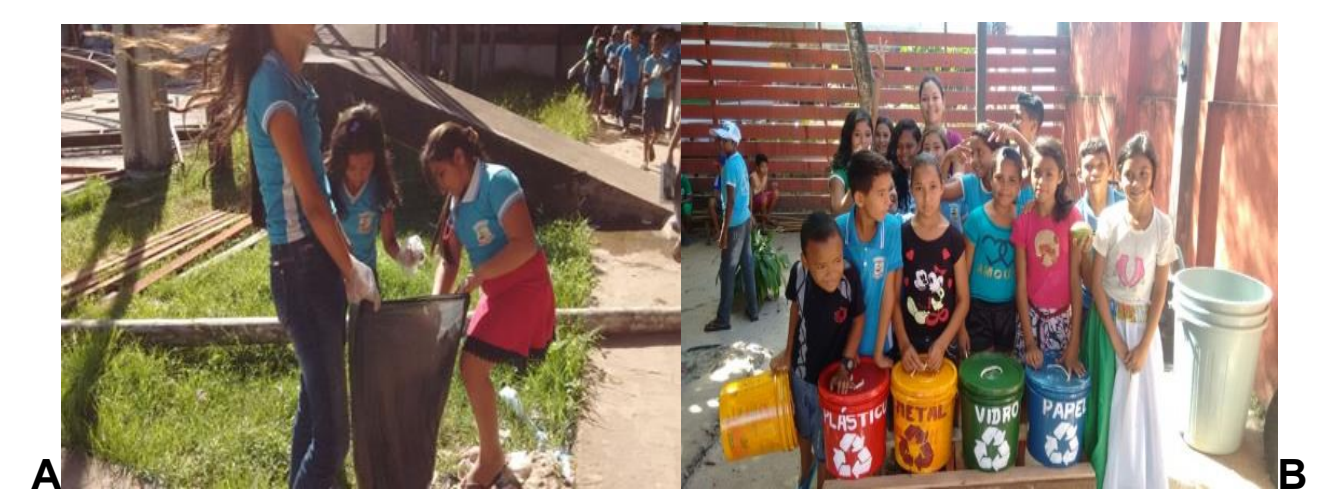

Figura 3: Alunas fazendo a coleta do lixo na escola, e recebendo ajuda de alunas de outras turmas no mutirão feito na escola $(A)$. Recipientes transformados em lixeiras, e distribuídos nas dependências da escola (B).

De acordo com SILVA (2007), o lixo é um elemento presente na vida de qualquer pessoa, sendo um tema a ser trabalhado com os alunos, de forma interdisciplinar, objetivando a conscientização e a mudança de atitudes dentro e fora da sala de aula, assumindo um papel preponderante na formação do sujeito 
e na sua inserção social, agindo com consciência e atitude perante os problemas do meio ambiente.

Após a reflexão, os alunos receberam a tarefa de confeccionar os próprios lixeiros para a coleta seletiva, com o objetivo de ressaltar a eles a importância da coleta e separação do lixo. Com médios recipientes com tampa, os alunos pintaram nas cores da coleta seletiva e nomearam os respectivos para que fossem colocados dentro da escola e servissem de incentivo aos outros alunos de utilizarem as lixeiras feitas pelos colegas (Figura 3b).

A mais cansativa e de grande absolvição de conhecimento, é ousado dizer até de construção cidadã dos alunos, foi a oficina de coleta seletiva. Foram feitos muitas colocações e perguntas sobre o resíduo orgânico e notou-se a grande apreciação deles com o fato de se separar o lixo por cores, de como pode ser divertido trabalhar com o lixo, no momento de receber as luvas e as sacolas de lixo, houve grande empenho e compromisso em coletar todo o lixo que encontrassem, deixando a escola mais limpa.

Durante a pesquisa foi observado que os discentes estavam mais atentos aos problemas que o acúmulo de lixo pode causar ao meio ambiente, as professoras cumpriram o próximo passo de incentivá-los a pensar em possíveis soluções para essa questão, mobilizando-os a separar o lixo em materiais recicláveis e não recicláveis, separando de acordo com a classificação universal (explicando que cada cor, em qualquer lugar do mundo, corresponde a um material: amarelo para metal; vermelho para plástico; azul para papel; verde para vidro; branco para lixo orgânico; e preto para outros tipos de materiais).

\section{$4^{\circ}$ DIA - 09/06 (quinta-feira): segunda oficina (oficina da reciclagem)}

Notou-se uma grande satisfação por parte das crianças, em estar trazendo para escola o material que se tornaria um brinquedo ou objeto para seu uso, e em mostrar aos seus colegas o quão estavam aprendendo com as oficinas, tendo em vista de que quando foram percebendo que aquele "lixo" por eles tragos, de repente e com um pouquinho de criatividade se transformavam em objetos dignos de ser exposto com orgulho à apreciação pública (Figura 4).

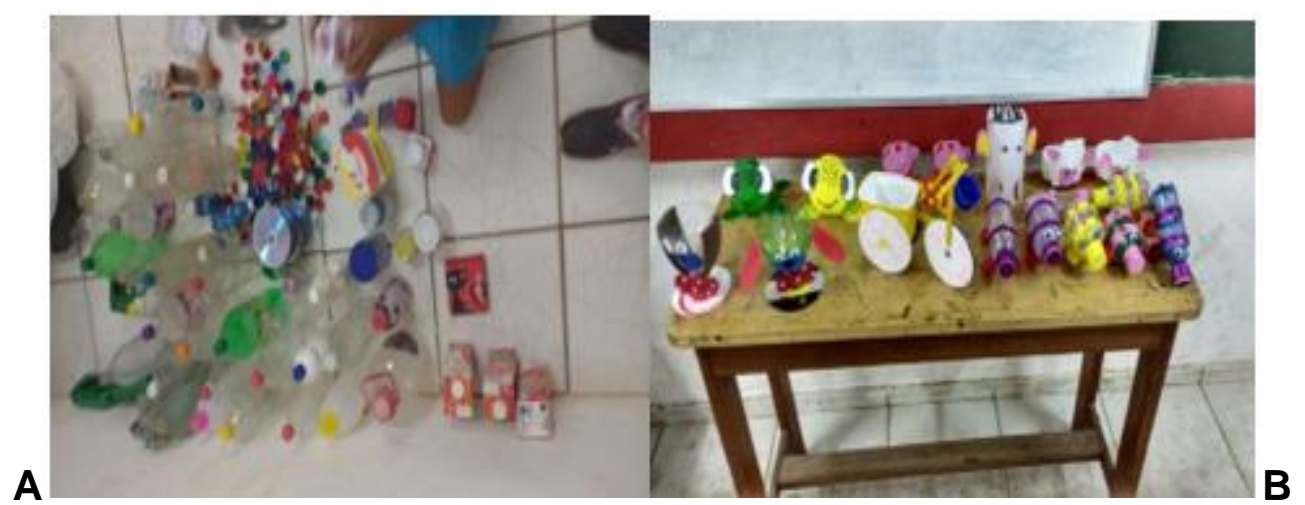

Figura 4: Materiais trazidos pelos alunos para serem reciclados na oficina $(A)$ e brinquedos e objetos confeccionados pelos alunos durante a oficina $(B)$. 
Um fato marcante observado durante a realização das oficinas foi a mudança de comportamento dos alunos com relação ao lixo. Isso foi observado quando se solicitou aos alunos que trouxessem para a primeira oficina as garrafas PET para serem aproveitadas e, apesar de todas as orientações com relação à limpeza das garrafas, a maioria dos alunos trouxeram-nas sujas e ficavam me aguardando no lado de fora do colégio, para que nenhum colega os visse chegar com o "lixo". Isso demonstrou a visão distorcida que os alunos possuíam do lixo, confirmando nossa hipótese de que eles percebiam o lixo como algo depreciativo, sujo, do qual eles se envergonhavam. Para a grande maioria deles, não estava associada ao lixo a ideia de matéria-prima e de fonte de criação de novos materiais e obras de arte. Nos primeiros dias do trabalho proposto, apesar da contextualização sobre o tema "lixo", a maioria dos participantes demonstrava certa resistência em trazer as "matérias-primas" (garrafas PET, embalagens longa vida e outros) solicitadas para 0 reaproveitamento, pois o constrangimento era maior, e frases como "eu não sou catador de lixo, professora”!", era muito comum. CASTRO (2008).

Nota-se que este fato se deu, devido à falta de uma preparação maior dos alunos para com o propósito de se trazer a garrafa pet, uma motivação a mais sobre o que seria feito e de que forma seria reproduzido para os outros alunos, pois a prática da Educação Ambiental pode ser repassada de diversas formas, cabe ao professor organizar e mediar o conteúdo ensinado, mobilizando afeto e desejo do aluno para que o mesmo se aproprie e transforme o conhecimento.

A ideia inicial do projeto de reciclar e reaproveitar matérias foram uma das possibilidades para se evitar a disposição inadequada dos resíduos sólidos disponíveis dentro da escola, e o empenho dos alunos com as atividades do projeto, foram as mais surpreendentes, dado até ao fato de muitos pedirem para que o projeto durasse mais tempo na escola ou que fosse feito de novo depois das férias de julho, é oportuno também comentar, que a mudança de comportamento foi observada nos professores e em outras pessoas que nem estavam observando as atividades do projeto, como as auxiliares da cozinha e os secretários. Quando estes funcionários da escola começaram a ver a movimentação dos alunos e o seu entusiasmo, começaram também a participar e incentivar os outros.

\section{$5^{\circ}$ DIA - 10/06 (sexta-feira): terceira oficina (oficina de horta e plantio)}

A oficina possibilitou o contato direto dos alunos com a terra, podendo preparar o solo, conhecer e associar os ciclos alimentares de semeadura, plantio, cultivo ter cuidado com as plantas, além de ser um momento em que os alunos aprenderam a respeitar a terra.

O Trabalho de construção da horta, o contato dos alunos com a terra e com as ferramentas utilizadas no manuseio e preparação da terra, foi bem recebido pelos, visto que a maioria é filho de agricultor ou em casa a mãe costuma cultivar hortaliças para o consumo da família e as crianças, 
principalmente as meninas acompanham esse processo e executam com satisfação.

A horta inserida no ambiente escolar pode ser um laboratório vivo que possibilita o desenvolvimento de diversas atividades pedagógicas em Educação Ambiental e alimentar unindo teoria e prática de forma contextualizada, auxiliando no processo de ensino-aprendizagem e estreitando relações através da promoção do trabalho coletivo e cooperado entre os agentes sociais envolvidos (MORGADO, 2008).

É importante ressaltar a valorização da agricultura familiar, inserida na execução da oficina, pois, faz com que o aluno aprenda também na escola, a valorizar o trabalho da família na agricultura, construindo uma visão sustentável e econômica de plantar e colher, produtos saudáveis e de boa qualidade. Segundo FRISK, 2008: Através deste projeto os alunos terão a oportunidade de conciliar teoria à prática, aplicando o que se aprende na sala de aula. Assim levarão uma experiência valiosa para vida, já que a saúde do homem está ligada a uma alimentação saudável e rica em vegetais.

\section{Questionário de avaliação}

O questionário teve a intenção de avaliar a percepção dos discentes envolvidos na execução do Projeto de Educação Ambiental realizado na Escola Agroambiental Professora Lindalva Pinho, no Município de Curralinho - Pará.

O questionário teve como vantagem economizar tempo, abranger grande número de dados, atingir maior número de respostas mais rápidas e exatas, mais tempo para responder; horário favorável, tornando-se um instrumento de coleta de dados constituído por uma série de perguntas, que devem ser respondidas por escrito. As perguntas foram utilizadas no levantamento das informações de avaliação dos alunos em relação ao desenvolvimento do projeto, aplicadas de forma direta com auxílio dos professores, como podemos observar a seguir:

\section{O que você achou do projeto de Educação Ambiental na escola?}

Conforme entrevista 28 (70\%) alunos afirmam ser excelente a iniciativa do projeto, $9(22,5 \%)$ alunos acham bom e 2 (5\%) alunos acham ruim, somente um aluno não respondeu essa pergunta, alguns afirmam que o projeto foi inovador e dinâmico.

"Eu gostei, porque a gente nunca teve nenhum trabalho assim na escola e agora sabemos por que devemos cuidar da escola e deixar ela limpa." (Rana de Souza Brito, aluna do 5은 ano/tarde).

Houve grande acolhimento do projeto na escola, todos os alunos e professores e até mesmo os que estão apenas assistindo, como funcionário e outros alunos e professores agradeceram e deixaram o espaço escolar à disposição para quando 
houver futuros projetos, este será bem-vindo à escola. Foi de fato, um instrumento de transformação tanto no comportamento em sala de aula, quanto na relação deles com o meio ambiente, fazendo valer que a escola ficava na orla da cidade de frente para o rio e muitos deles passaram a observar as coisas erradas que outras pessoas faziam ali, despejando lixo no rio. Concordando com Santos (2014).

Assim sendo é fundamental que a Educação Ambiental seja trabalhada e discutida nas escolas, pois desta forma os alunos não apenas conhecerão o meio ambiente como se ensina em algumas disciplinas específicas, mas aprendam a valorizar, preservar, respeitar o meio ambiente que ele mesmo se encontra, de forma com que sejam agentes ativos e modificadores, capazes de tomar posição e reverter a situação degradante que vivemos.

\section{Você aprendeu algo importante para sua vida?}

Observa-se que 36 (90\%) aprenderam a separar o lixo de acordo com a sua classificação, para não jogar lixo no lugar errado e não misturar resíduo orgânico do sólido, a reduzir e reciclar o lixo na escola, através das oficinas de reciclagem, onde ao fim da exposição cada um levou para casa seu trabalho, para construir mais objetos e brinquedos e compartilhar o aprendizado com outros colegas. Um fato marcante observado durante a realização das oficinas foi a mudança de comportamento dos alunos com relação ao lixo, notou-se essa mudança já no terceiro dia de atividades.

Por outro lado, foram observadas as duas atividades que mais os alunos gostaram a oficina de plantio, onde puderam mexer com a terra, construir a horta e cada um plantar a sua muda, na esperança que futuramente venha encontrar as hortaliças em sua merenda escolar e a oficina de reciclagem, onde puderam conhecer e aprender várias formas de se transformar o lixo. Três alunos (7,5\%) relataram que não aprenderam nada no curso, infelizmente houve certo desinteresse da parte de alguns alunos que no dia das palestras, saíram da sala e se recusaram a participar das oficinas, e somente um aluno não respondeu essa pergunta.

\section{Você indica as atividades do projeto para outras turmas e escolas?}

Nesta pesquisa,38 alunos (95\%) dos entrevistados falaram que sim, afirmando que gostaram da iniciativa dizendo que nunca viram nada igual em outro estabelecimento escolar. E somente (2) $5 \%$ afirmam que não.

Seria muito bom se a escola toda e outras escolas do município pudessem participar do projeto, para que aprender a fazer brinquedos e jogos a partir do nosso lixo (Vinicius de Carvalho Moraes, aluno do $5^{\circ}$ ano/tarde).

Adotar o projeto em outras escolas representaria um grande benefício na formação dos alunos, aprendendo metodologias sustentáveis e se tronando multiplicadores, passando a trabalhar a Educação Ambiental, não só como forma de projeto, mas como disciplina na sua grade curricular. 
Com a publicação da Lei 9.795, de 27/4/99, que dispõe sobre a Educação Ambiental, institui a Política Nacional de Educação Ambiental e dar outras providências, a questão tomou força, pois a implantação e aplicação da Educação Ambiental como disciplina passou a ser obrigatória. A citada lei define juridicamente Educação Ambiental como "o processo por meio do qual o indivíduo e a coletividade constroem valores sociais, conhecimentos, habilidades, atitudes e competências voltadas para a conservação do meio ambiente, bem de uso comum do povo, essencial à sadia qualidade de vida $e$ sua sustentabilidade" (art.1ํ).

\section{O projeto ajudou nas suas atividades escolares?}

Nota-se que $97,5 \%$ dos alunos aceitaram as atividades desenvolvidas no projeto e demonstraram boa aceitação e que ajudaram nas atividades da escola, tanto como forma de avaliação escolhida pelos professores, como no trabalho em conjunto exercido dentro e fora da escola e somente 1 aluno relatou que não, porque não conseguiu acompanhar e finalizar nenhuma atividade juntos com os outros alunos.

A prática da Educação Ambiental pode ser repassada de diversas formas, cabe ao professor organizar e mediar o conteúdo ensinado, mobilizando afeto e desejo do aluno para que o mesmo se aproprie e transforme o conhecimento. É de suma importância a base emotiva na relação professor e aluno, pois surge a dedicação e compromisso que complementam os conhecimentos na busca do indivíduo por uma melhor qualidade de vida (TRINDADE, 2011)

Segundo os professores, os alunos passaram a falar mais durante os assuntos na sala, questionar e acrescentar opiniões sentiram que os alunos ficaram mais desinibidos com as dinâmicas que o projeto estabelecia a eles, em momentos que cada um devia falar e escutar. $O$ entra e sai de sala também não se notava mais, $o$ ato de arrumar as cadeiras da sala quando chegavam durante o projeto, hoje ainda continua fazendo em alguns dias. Isso demonstra como foi modificador e positiva a passagem do projeto na turma.

\section{Em sua opinião, essas atividades são suficientes?}

Identifica-se que 52,5\% dos entrevistados (21alunos) afirmam que sim, pois desencadearam uma serie de aprendizado com os trabalhos desenvolvidos e durante as palestras muitos mostraram domínios dos assuntos abordados, e que as palestras serviram muito mais para reforçar o conhecimento deles, do que ensinar, e 47,5\% (19) afirmam que não.

Devido ao curto tempo de duração das atividades que foram em apenas 06 dias, muitos deles pediram para que se estendesse por mais dias, pois estavam gostando e aprendendo, mas o tempo disponibilizado pela escola foi apenas de 06 dias, mais do que isso poderia atrapalhar as avaliações das turmas. Em virtude disso, foi feito o convite para que o projeto fosse executado 
em toda a escola, abrangendo todas as turmas e professores, tendo em vista que a escola trazendo uma proposta Agroambiental, não exercia nenhuma atividade de tal gênero.

\section{Você prática algumas das atividades de Educação Ambiental do projeto?}

Para 90\% (36) dos alunos entrevistados, relatam que praticam as atividades de deposição do lixo em lugares adequados, economizam água e energia em casa e incentivam sua família a seguir da mesma forma, e observam as ações certas e erradas ao seu redor em relação à Educação Ambiental.

\footnotetext{
"Agora eu ando na rua e fico olhando quem joga lixo no chão e fico feliz quando alguém procura uma lixeira e não joga lixono rio."(Sadrak Nogueira

Cavalcanti, aluno do $5^{\circ}$ ano/tarde).

"eu sempre que tomo banho ou escovo os dentes, desligo a água pra não estragar, e a minha mãe briga e diz que não pode desperdiça rágua."

(Beatriz Pereira dos Santos, aluna do 5ํㅜㄴ ano/tarde).
}

Entretanto 10 alunos (4\%) não praticam. Isso se deu a grande preocupação dos educadores e pais dos alunos em participarem com temas sobre a sustentabilidade do meio em que vivem.

A Educação Ambiental, não se faz somente durante o projeto na sala de aula, é um processo contínuo, em que haja prática e prazer em tomar atitudes que vá trazer melhorias ao meio ambiente em que vivemos. $E$ foi notado que muitos daqueles alunos, ao final do projeto teriam atitudes diferentes em relação a jogar lixo no lugar certo, economizar água, ser mais consciente e educado, se policiar quanto a seus hábitos e de seus colegas. Dessa forma, as mudanças comportamentais. Segundo Reigota (1994), devem acima de tudo, levar os indivíduos e os grupos a adquirir o sentido dos valores sociais, um sentimento profundo de interesse pelo meio ambiente e a vontade de contribuir para a sua proteção e qualidade.

O resultado do projeto é evidentemente positivo. Considerando a participação dos alunos nas atividades do projeto, pode-se dizer que, a princípio, realizou-se com certo grau de desconfiança por parte deles. Fato este que se evidencia pelo pequeno número de alunos que não se interessaram com afinco pelo trabalho. Mas, logo no início do segundo dia de atividades já se podia notar o grau de interesse e conscientização por parte dos alunos através do diálogo e interação com eles mesmos, que se indagavam a respeito do que faziam e até 
denunciavam quem jogava lixo fora do lugar adequado. Houve também grande assimilação do conteúdo proposto nas palestras, que pôde ser percebido nas oficinas executadas, onde muitos alunos pareciam instigados a participar da construção de uma escola mais limpa e preservada.

Para responder a temática buscou-se apresentar a importância da reciclagem do lixo dentro da educação nas escolas. Buscando despertar a sociedade para a grande necessidade de se preocupar com o meio ambiente e com o futuro do nosso planeta. Houve grande desempenho nas oficinas de Coleta Seletiva e Reciclagem, percebeu-se o momento que os alunos se sentiram mais agentes colaboradores de um ambiente limpo e abraçaram com grande afinco as mudanças de hábitos dentro da escola, com entusiasmo e trabalho em equipe. O projeto culminou com uma exposição dos trabalhos de reciclagem feitos pelos alunos que participaram da intervenção na escola no qual foram apresentados aos pais, colegas, professores e toda a comunidade que foi apreciar o trabalho desenvolvido.

Foi observado que os professores preocupados em seguir rigorosamente o planejamento curricular da disciplina, não criam espaços para a discussão ambiental. Quando esses momentos são organizados nas escolas, é comum que se modifique a organização habitual da sala de aula, nas quais os alunos ficam sentados e em silencio. Assim atividades extracurriculares ou que fogem do conteúdo tradicional são entendias como indisciplina. $O$ próprio desconhecimento dos professores acerca do tema meio ambiente e Educação Ambiental contribuem para as percepções distorcidas (CASTRO, 2008).

Dar-se a entender que a ideia de trabalhar a Educação Ambiental, é uma perda de tempo, atrapalha o desenvolvimento dos conteúdos, eles fazem uma relação direta e imediata com algum conteúdo especifica da disciplina, que esteja no seu conteúdo programático, é como se eles precisassem de uma "licença" para trazer a discussão ambiental para dentro das suas aulas, pois não está presente na sua grade curricular.

Foi constata a ausência dessa temática, do uso de técnicas em que o professor trabalhasse a Educação Ambiental em sala de aula e fora dela, conforme relatado pelos professores, o Projeto de Educação Ambiental foi a primeira programação a ser trabalhada exclusivamente com práticas fora da sala de aula e com dinâmicas acessíveis para os alunos, onde a maioria conseguiu assimilar a proposta do projeto e houve grande participação.

\section{Conclusões}

As atividades de coleta seletiva, oficinas de reciclagem e plantio de hortas é de fundamental importância para a sociedade e o meio ambiente, dessa forma espera-se que sejam de total aproveitamento e levadas para outros espaços, que a escola dê continuidade e que sirva de exemplo para outras escolas desenvolverem práticas de melhoria sustentável e para as famílias. Com o mesmo propósito que este projeto está sendo aplicado para a formação de 
cidadãos conscientes da preservação do meio ambiente, e estarem aptos a executar pequenas ações coletivas de cuidados com o meio em que vivem para que no futuro construam uma sociedade sustentável.

A necessidade de formar e aperfeiçoar docentes e discentes de todos os níveis é imprescindível para que se projete no futuro um profundo envolvimento da educação formal com o meio ambiente. Só assim será possível gerar reflexões, discussões e práticas que, efetivamente, conduzirão a uma Educação Ambiental de qualidade e mostrar a importância de preservar do meio ambiente, reciclar, realizar a coleta seletiva dos resíduos sólidos, plantio de hortas.

\section{Referências}

AMBIENTE BRASIL. Educação Ambiental. Manaus - AM, 2008. Disponível em: www.ambientebrasil.com. Acesso em: 17 de Mai. De 2016

BRASIL. Ministério da Educação. Secretaria da Educação Fundamental. Média e Tecnológica. Parâmetros Curriculares Nacionais + $(\mathrm{PCN}+)$-. Meio ambiente, saúde. Vol.9. Brasília: MEC, 2002. 128p.

BRASIL. MEC. Panorama da Educação Ambiental no ensino fundamental. Brasília: MEC/SEF, 2001.

BRASIL. MEC. Política Nacional de Educação Ambiental. Lei o 9.795 de 27 de abril de 1999. Dispõe sobre a Educação Ambiental, institui a Política Nacional de Educação Ambiental e dá outras providências. Diário Oficial da União, Brasília, DF, 28 de abril de 1999. Seção 1, p.41. Disponível em: <EDUCAÇÃO AMBIENTALIPNEA 2.pdf>. Acesso em 17. Abr. 2016.

CARVALHO, I. C. M. Educação Ambiental: a formação do sujeito ecológico. 2.ed. São Paulo: Cortez, 2006. (Coleção Docência em formação).

CASTRO, M. A. A Reciclagem no contexto escolar. Ponta Grossa - PR, 2008. Disponível em: < EDUCACCÃO AMBIENTALIreciclagem no contexto escolar.pdf> Acesso em: 09 de ago de 2016

CHALITA, G. Educação: a solução está no afeto. São Paulo: Editora Gente, 2002. [S.I.] p. 272.

CICHELLA, F.; COELHO, J. M. S.; RESENDES, L. M. Educação Ambiental: Direcionando a busca. 2007. Disponível em: http://www.satc.edu.br/satc/fotos/ 2007/860/3 forum ambiental.pdf> Acesso em: 22 Mai 2016.

CUBA, M. A. Educação Ambiental nas Escolas. ECCOM, v. 1, n. 2, p. 23-31, jul./dez., 2010. Universidade de FATEA, Lorena/SP

EFFTING, T.R. Educação Ambiental nas escolas públicas: realidade e desafios. Monografia (Especialização em Planejamento para o Desenvolvimento sustentável) - Universidade Estadual do Oeste do Paraná, Marechal Cândido Rondon, 2007. Disponível em: EDUCAÇÃO AMBIENTALIEducação Ambiental nas escolas, desafios - artigo.pdf> Acesso em: 20 de abril de 2016. 
FRISK, P. R; Horta na Escola; Publicado, 2008. Disponível em: <EDUCAÇÃO AMBIENTALlfriskdesenvolvimento escolar HORTA.pdf> Acesso em 02 de ago de 2016.

GUIMARÃES, M. A dimensão ambiental na educação. Campinas. Papirus, 1995. 107p. (Coleção Magistério: Formação e trabalho pedagógico). Disponível em: A dimensão ambiental na educação. Campinas. Acesso em: 20 de abril de 2016.

LIMA, G. F. C. Identidades da Educação Ambiental brasileira. Ministério do Meio Ambiente, 2004.

MEDEIROS, A.B. et al. A Importância da Educação Ambiental na escola nas séries iniciais. Revista Faculdade Montes Belos, v. 4, n. 1, set. 2011

MORGADO, F; S. A Horta Escolar na Educação Ambiental e Alimentar: Experiência do Projeto Horta Viva nas Escolas Municipais de Florianópolis, 2008. Disponível em: http://www.extensio.ufsc.br/20081/A-hortaescolar. pdf> Acesso em 02 de ago 2016.

MULLER, L. S. A interação professor-aluno no processo educativo. São Paulo, 2002. 276p. disponível em: http://www.usit.br/proex/arquivos/produtos academicos/276 31.pdf> Acesso em: 20 de abril de 2016.

REIGOTA, M. O que é Educação Ambiental? São Paulo: Ed. Brasiliense, 1994.

SALERA JUNIOR, G. Educação Ambiental. Gurupi - TO, 2009. Disponível em: $<$ http://www.recantodasletras.com.br/e-livros/1966292> Acesso em: 15 Abr. de 2016

SANTOS, A. S. Como a educação ambiental está sendo trabalhada em cabedelo? um estudo de caso na Escola Municipal Silvana Oliveira Pontes. Cabedelo-PB, 2014. Disponível em: EDUCAÇÃO AMBIENTALISANTOS- A. S. Como a Educação Ambiental...pdf > Acesso em: 20 de abril de 2016.

SILVA, D. T. S. Educação Ambiental: Coleta Seletiva e Reciclagem de Resíduos Sólidos na Escola. Cachoeirinha-RS: FASB, 2007.

SOUZA, G. S. ; MACHADO, P. B.; REIS, V. R..; SANTOS, A. S.; DIAS, V. B. Educação Ambiental como ferramenta para o manejo de resíduos sólidos no cotidiano escolar. RevBea, Rio Grande, V. 8, N. 2:118-130, 2013.

SOUZA, P. P. S. de; PEREIRA, J. L. de G. Representação social de meio ambiente e Educação Ambiental nas escolas públicas de Teófilo Otoni - MG. RevBea, Rio Grande, n. 6, p. 35-40, 2011. Disponível em: http:/www.seer.furg.br/ revbea/article/view/2031/1040>. Acesso em: 20 de maio de 2016

TRINDADE, N. A. D. Consciência ambiental: coleta seletiva e reciclagem no ambiente escolar. Itapetinga - BA, 2011. ENCICLOPÉDIA BIOSFERA, Centro Científico Conhecer - Goiânia, vol.7, n.12; 2011. 